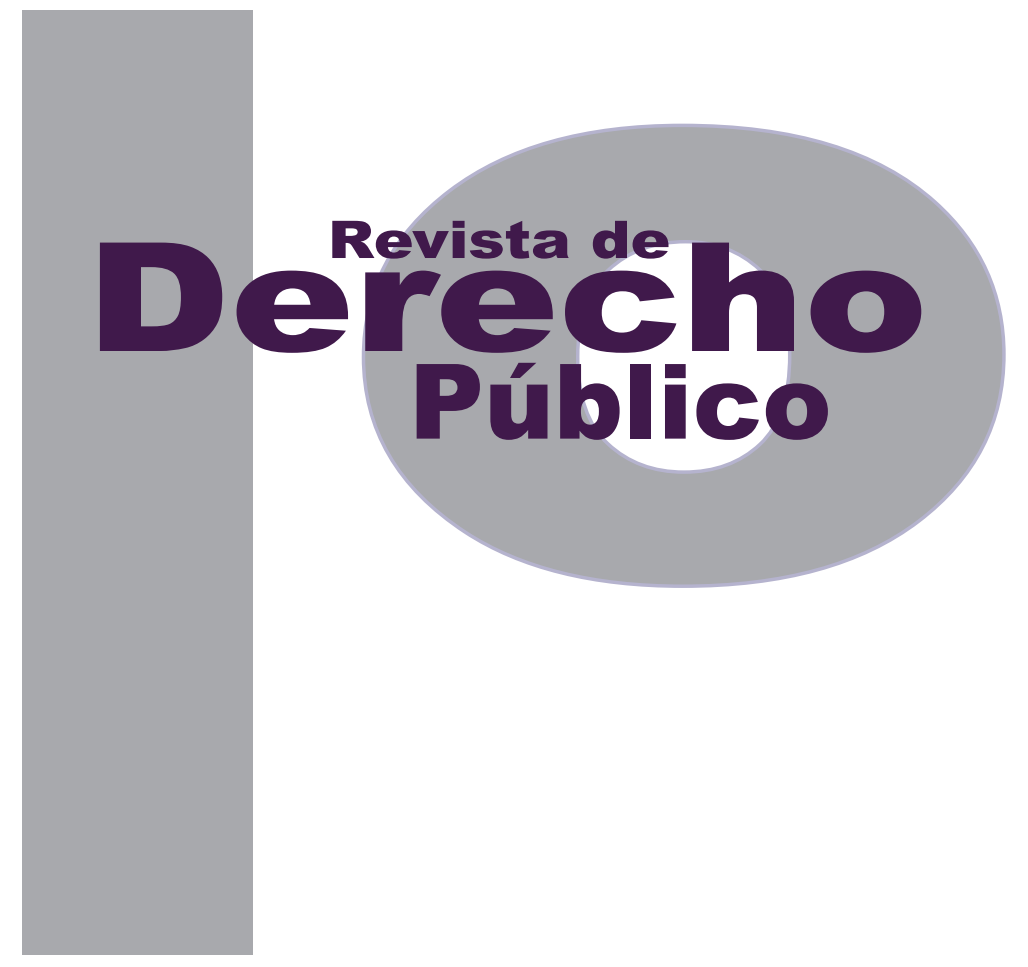

\title{
LA CONSTRUCCIÓN DEL SUJETO COLECTIVO AFROCOLOMBIANO: LECCIONES DE UNA CONSULTA
}

Eliana fernanda Antonio Rosero

Universidad de los Andes

Facultad de Derecho

Revista de Derecho Público N. ${ }^{\circ} 31$

Julio - Diciembre de 2013. ISSN 1909-7778 


\title{
La construcción del sujeto colectivo afrocolombiano: lecciones de una consulta*
}

\author{
Eliana Fernanda Antonio Rosero**
}

\section{RESUMEN}

Este artículo es un relato y, a la vez, reflexión sobre lo que fue el proceso de consulta previa del decreto reglamentario para víctimas negras, afrocolombianas, palenqueras y raizales en el marco de la Ley 1448 de 2011 o Ley de Víctimas. El relato se basa tanto en la revisión de normas legales, artículos de prensa y otros documentos publicados por el Gobierno y organizaciones afrocolombianas como en mi propia experiencia como abogada del Proceso de Comunidades Negras que articula diversas organizaciones sociales afrocolombianas. A través de la narración de lo sucedido se muestran los re-
This article is a report and a reflection on what was the prior consultation process regarding the decree on black, afrocolombian, palenquera and raizales victims, as part of the 1448 law of 2011 or Victim Act (Ley de Víctimas). The narrative is based on both the review of legislation, press releases and other documents published by the government and Afro-Colombian organizations and in my own experience as a lawyer in the Process of Black Communities (PCN), network that coordinates various Afro-Colombian social organizations. Through the story of what happened, the paper shows the challenges and

Cómo citar este artículo: Antonio Rosero, E. F. (Diciembre, 2013). La construcción del sujeto colectivo afrocolombiano: lecciones de una consulta. Revista de Derecho Público, 31 
tos y dificultades de dicha consulta, en especial los problemas para identificar un interlocutor legítimo que los represente en un proceso de consulta previa de normas de carácter nacional, y la falta de participación de la base en la consulta.

PALABRAS ClaVe: consulta previa, afrocolombianos, Ley de Víctimas. difficulties of such consultation, especially the difficulties to identify a legitimate interlocutor, chose and appointed by the community, and the lack of grassroots participation in the process.

KEY WORDS: black community, victims law, previous consultation. 


\section{SUMARIO}

Introducción - I. LA DIFICULTAD PARA IDENTIFICAR UN INTERLOCUTOR LEGITIMO ¿QUIÉN REPRESENTA A LOS AFROCOLOMBIANOS? - II. EL CASO DE LA CONSULTA DEL DECRETO-LEY - III. ¿CÓMO HACER LA CONSULTA CON EL SUJETO COLECTIVO AFROCOLOMBIANO? CONSIDERACIONES PARA UNA PROPUESTA DE REGLAMENTACIÓN - A. Primer paso: identificar las comunidades donde se realizará la consulta - B. Segundo paso: identificación de los actores en cada comunidad - C. Tercer paso: garantizar el suficiente tiempo en cada proceso de consulta - D. Cuarto paso: garantizar una adecuada respuesta del Gobierno a las decisiones de la población afrocolombiana - E. Precondición: garantizar la adecuada financiación de la consulta - IV. CONCLUSIÓN: LECCIONES APRENDIDAS DENTRO DE LOS PROCESOS DE CONSULTA - Bibliografía. 
Introducción

A raíz de la declaratoria de inconstitucionalidad de la Ley Forestal (Ley 1021 de 2006) y del Código Minero (Ley 1382 de 2010), el Gobierno ha aceptado la necesidad de realizar la consulta previa de aquellas normas de nivel nacional que afectan a la población afrocolombiana e indígena. Así, en el transcurso del proceso que llevó a la expedición de la Ley de Víctimas (Ley 1448 de 2011), la coalición de gobierno, la llamada Unidad Nacional, se vio abocada a cumplir con el requisito de adelantar la consulta previa con las minorías étnicas. Ante la preocupación por la declaratoria de inconstitucionalidad, el Congreso aprobó el artículo 205 de la Ley 1448 de 2011 que traslada la responsabilidad de consultar la Ley de Víctimas al Gobierno Nacional, quien se comprometió a hacerlo, debidamente, con los pueblos indígenas, la población afrocolombiana y el pueblo Rom.

Pero la aceptación de la consulta no resuelve una pregunta fundamental: ¿cómo hacer esta consulta con un sujeto colectivo de escala nacional que no está claramente identificado y con quien no se ha concertado quién lo representa de forma legítima? En el caso de los afrocolombianos, cuando se mide la autoidenficación por raza se llega a una población de 4.311.757 millones de personas (DANE-CIDSE, 2005), pero si se plantea el sujeto colectivo en su concepción más estrecha, se encuentra que está constituido por la población de los 173 Consejos Comunitarios reconocidos por el Gobierno por contar con una titulación colectiva vigente (Wabgou, Arocha, Salgado y Carabalí, 2012); en estos
Consejos se estima una población de 332.589 personas (Urrea y Viáfara, 2012). Esto sin tener en cuenta la multiplicidad de organizaciones que se autoidentifican como afrocolombianas. La respuesta a la pregunta de cómo consultar a un sujeto de esta envergadura está, sin duda, en construcción.

Este artículo pretende contribuir a dar respuesta al cómo consultar al sujeto colectivo afrocolombiano, a partir de la experiencia de las organizaciones que participaron en el reciente proceso de consulta del decreto reglamentario de la Ley de Víctimas. El relato se basa tanto en la revisión de normas legales, artículos de prensa y otros documentos publicados por el Gobierno y organizaciones afrocolombianas como en mi propia experiencia como abogada del Proceso de Comunidades Negras (PCN), organización nacional que está conformada por 120 organizaciones étnico-territoriales, entre Consejos Comunitarios y organizaciones de base de mujeres, jóvenes, agremiaciones culturales y etnoeducadores. A través de la narración de lo sucedido se muestran los retos y dificultades de dicha consulta, en especial los obstáculos para identificar un interlocutor legítimo a la hora de pedir el concepto sobre normas de carácter nacional, y la falta de participación de la base en la consulta.

Además, el artículo señala las lecciones que tanto las organizaciones como el Gobierno deben aprender de esta experiencia: primera, que estos procesos deben compadecerse con los tiempos de consulta y deliberación de las comunidades, tiempos que además son los que per- 
miten la consolidación de interlocutores válidos; segunda, la necesidad de consolidar una ruta de consulta de normas del nivel nacional que pueda ser utilizada en diversos procesos, en lugar de crear la ruta en cada ocasión; tercera, la necesidad de reconocer la existencia de dos tipos de identidades al interior de esta población: una que corresponde al componente racial de autoidentificación como afrocolombiano pero desarrollado a partir de un componente urbano, y otra cuya relación con el territorio ancestral es fundamental para la supervivencia. Estas identidades no son excluyentes y son igualmente sujetos de procesos de consulta previa

Así mismo, es esencial el reconocimiento de la existencia de un tercer tipo de afrodescendientes: aquellos que a pesar de ser identificados fenotípicamente por otros como afrodescendientes no se autoidentifican como tales (Fanon, 2009 , p. 163). Teniendo en cuenta que estas personas no han desarrollado una identidad individual ni colectiva afrodescendiente no serían sujeto de la consulta previa.

\section{LA DIFICULTAD PARA IDENTIFICAR UN INTERLOCUTOR LEGÍTIMO ¿QUIÉN REPRESENTA A LOS AFROCOLOMBIANOS?}

Una de las dificultades iniciales dentro del proceso de la consulta previa corresponde a la identificación de los afrocolombianos que deberán ser parte del proceso. Una posibilidad es hacerlo de acuerdo con la autoidentificación racial efectuada en el censo nacional. Sin embargo, esta alternativa resulta una tarea titánica, que empieza por ubicar a cada persona que se autorreconozca como afrodescendiente y que implica, además, determinar si cumple o no con los dos criterios establecidos en la sentencia C-169 de 2001 que desarrolla los elementos objetivo y subjetivo necesarios para identificar a una colectividad o individuo como parte de un grupo tribal o étnico: "El elemento "objetivo" corresponde a la existencia de rasgos culturales y sociales compartidos por los miembros del grupo, que les diferencien de los demás sectores sociales, y el elemento "subjetivo", que implica la existencia de una identidad grupal que lleve a los individuos a asumirse como miembros de la colectividad en cuestión". Esta alternativa es, de plano, imposible.

Una segunda posibilidad para determinar un interlocutor del Gobierno Nacional en un proceso de consulta previa es identificar como afrocolombianos solamente a aquellos que pertenezcan a un Consejo Comunitario. En este caso, el dilema está en que algunas de estas colectividades afrocolombianas (organizaciones, agremiaciones, comunidades sin título colectivo, colectivos urbanos y otras que cumplen los requisitos de la sentencia C-169 de 2001, pero no están reconocidas como Consejo Comunitario con título colectivo) tienen su asentamiento en zonas urbanas donde no se reconoce la existencia de los Consejos Comunitarios y donde no suelen otorgarse títulos colectivos, tal como ocurre con la población afrocolombiana de Agua Blanca, en Cali. De igual manera se estaría excluyendo a aquellas personas y comunidades que se vieron obligadas a desplazarse de sus territorios y tras- 
ladarse a grandes urbes donde mantienen sus rasgos culturales y sociales, su identidad colectiva y su identidad racial.

Una tercera posibilidad por la que aboga este artículo es que cuando la consulta previa corresponda a proyectos de ley o propuestas del orden nacional como los planes de desarrollo o en este caso la Ley de Víctimas, el proceso de consulta siga una ruta preestablecida inspirada en los elementos objetivos y subjetivos de la sentencia citada. Para ello se sugiere crear espacios en los lugares donde se sabe que existen comunidades con los rasgos culturales y raciales mencionados en la sentencia C-169 de 2001, a donde puedan acudir las personas que se autoidentifican como afrocolombianas.

Así, la convocatoria para la consulta previa se debe dividir de manera territorial incluyendo urbes, zonas rurales e islas, asegurando que los sitios de encuentro faciliten la participación de comunidades rurales y colectivos urbanos; este punto es crucial para permitir la identificación de interlocutores. En igual sentido se debe asegurar: la concientización sobre el proceso de consulta como mecanismo para garantizarles el goce y protección de sus derechos diferenciales; el conocimiento previo de los temas que se van a consultar, mediante la difusión del texto del proyecto de ley en los diferentes focos territoriales establecidos utilizando diferentes estrategias -obras de teatro, cuentos, novelas, canciones y diversas alternativas didácticas- como las que se implementaron para el proceso de elaboración y reglamentación de la Ley 70 de 1993. Al garantizar una información y conocimiento de los textos (aspectos positivos y problemáticos) adecuada a las bases es posible que no sea necesario convocar a la consulta a los 4.311.757 millones de personas, sino que las comunidades y colectivos designen emisarios con decisiones puntuales sobre los temas objeto de la consulta.

Una vez identificado el sujeto afrocolombiano a consultar, surge una dificultad quizá más grande: establecer quién representa este sujeto tan grande y diverso. La consulta del decreto ley de la Ley de Víctimas para la población afrocolombiana llevó el problema de la representación más allá del tema de la constitución del sujeto mismo. La pregunta giró en torno a quién lo representaba y cómo. Fueron constantes las disputas entre la Comisión Consultiva creada por la Ley 70 de 1993, los intelectuales y los líderes afrocolombianos que abogaban por un tipo de representación más cercano a sus formas tradicionales de liderazgo.

El tema de la representación se ve agravado por una especificidad cultural: tradicionalmente en las comunidades negras, afrocolombianas, palenqueras y raizales no se habla de un líder que sea su representante y pueda decidir en nombre de la colectividad; se habla de unos emisarios que ejercen un liderazgo en materia de interlocución, pero no de una cesión de la representación, es decir, aquella persona que ejerce el liderazgo en una comunidad en particular es la encargada de recibir la información, trasmitirla a la colectividad y facilitar los espacios, medios y recursos para que sus miembros tengan el tiempo necesario para analizar e interpretar 
la información recibida y llegar a una decisión (Palenque regional El Congal, 2008a; Afrodescendientes, 2013). Así, un interlocutor legítimo (emisario) de comunidades negras, afrocolombianas, palenqueras y raizales entiende que su papel no es decidir por la comunidad sino facilitar los espacios, los tiempos, los medios y recursos que le permitan a la comunidad tomar una buena decisión. (Palenque regional El Congal, 2008a; Afrodescendientes, 2013). Por ello, la consulta debe realizarse directamente con las comunidades y no con sus emisarios.

Este tipo de interlocución genera, por supuesto, dificultades para la forma hegemónica de ejercer la representación política, esto es, poder efectivamente hablar por los demás (Semana, 2011). La necesidad de los gobiernos de turno de identificar un interlocutor o un representante de las comunidades negras, afrocolombianas, palenqueras y raizales surgió con el artículo transitorio 55 de la Constitución Nacional, y más específicamente cuando el Congreso, en cumplimiento de lo ordenado en dicho artículo, expidió la Ley 70 de 1993, que en el artículo 45 estableció la creación de una Comisión Consultiva que fungiera como su espacio de representación: “El Gobierno Nacional conformará una Comisión Consultiva de alto nivel, con la participación de representantes de las comunidades negras de Antioquia, Valle, Cauca, Chocó, Nariño, Costa Atlántica y demás regiones del país a que se refiere esta ley y de raizales de San Andrés, Providencia y Santa Catalina, para el seguimiento de lo dispuesto en la presente ley".

Sin embargo, tanto el mecanismo de elección de los integrantes de esta Comisión Consultiva como sus funciones quedaron abiertas a una posterior reglamentación. La Ley en comento en su artículo 46 solo señala: "Los Consejos Comunitarios podrán designar por consenso los representantes de los beneficiarios de esta ley para los efectos que se requiera"; tampoco identifica a esta Comisión como el interlocutor válido para los procesos de consulta previa, ya que en 1993 el tema no figuraba en la agenda política, en cambio, el artículo 45 sí le asigna funciones para facilitar los procesos de titulación colectiva y su propia reglamentación (Ley 70 de 1993). En los años posteriores surgió la duda sobre si la Comisión Consultiva representaba o no al sujeto colectivo afrocolombiano y cuál era el contenido de esta representación, es decir, si se trataba del tradicional liderazgo de mediación o si debía entenderse a la manera de las instituciones occidentales.

La Comisión Consultiva se conformó en 1994, mediante el Decreto 1371 que reglamentó sus integrantes, sus funciones y su naturaleza, como consta en el tercer considerando: “La Comisión Consultiva de Alto Nivel debe constituirse además en espacio de interlocución permanente para la atención de los asuntos de carácter regional y nacional que interesan a las comunidades negras beneficiarias de la Ley 70 de 1993". Tampoco estas facultades fueron consultadas con las comunidades negras.

Como se puede apreciar en el cuadro 1, la Comisión Consultiva de Alto Nivel fue siendo modificada de manera sistemática por los gobiernos de turno para convertirla en instancia de representación de las comunidades negras, pero sin 
contar con la participación de estas, es decir, se definió la representación sin el consentimiento del representado; ahí nace uno de los mayores obstáculos para el reconocimiento por parte de las comunidades negras, afrocolombianas paIenqueras y raizales, de la Comisión Consultiva de Alto Nivel como su interlocutor legítimo.

\begin{tabular}{|c|c|c|c|}
\hline Decreto 1371 de 1994 & Decreto 2248 de 1995 & Decreto 3770 de 2008 & $\begin{array}{l}\text { Surtió la con- } \\
\text { sulta previa }\end{array}$ \\
\hline $\begin{array}{l}\text { Servir de instancia de diálogo } \\
\text { entre las Comunidades Negras y } \\
\text { el Gobierno Nacional; }\end{array}$ & & $\begin{array}{l}\text { Servir de instancia de diálogo, } \\
\text { concertación e interlocución entre } \\
\text { las comunidades que representan } \\
\text { (sic) y el Gobierno Nacional. }\end{array}$ & No \\
\hline $\begin{array}{l}\text { 2. Constituirse en mecanismo } \\
\text { de difusión de la información } \\
\text { oficial hacia las comunidades } \\
\text { negras y de interlocución con } \\
\text { niveles directivos del orden } \\
\text { nacional; }\end{array}$ & & $\begin{array}{l}\text { Constituirse en mecanismo de } \\
\text { difusión de la información oficial } \\
\text { hacia las comunidades que rep- } \\
\text { resentan (sic) y de interlocución } \\
\text { con niveles directivos del orden } \\
\text { nacional. }\end{array}$ & No \\
\hline $\begin{array}{l}\text { 3. Promover, impulsar, hacer } \\
\text { seguimiento y evaluación a las } \\
\text { normas que desarrollan los } \\
\text { derechos de las comunidades } \\
\text { negras; }\end{array}$ & & $\begin{array}{l}\text { Promover, impulsar, hacer segui- } \\
\text { miento y evaluación a las normas } \\
\text { que desarrollan los derechos de } \\
\text { las comunidades que representan } \\
\text { (sic). }\end{array}$ & No \\
\hline $\begin{array}{l}\text { 4. Contribuir a la solución de los } \\
\text { problemas de tierrasque afectan } \\
\text { a las Comunidades Negras, } \\
\text { para impulsar programas de } \\
\text { titulación y dotación de tierras } \\
\text { en su beneficio, de acuerdo con } \\
\text { la ley; }\end{array}$ & $\begin{array}{l}\text { 4. Contribuir a la solución de } \\
\text { los problemas de tierras que } \\
\text { afectan a las comunidades } \\
\text { negras de todo el país e } \\
\text { impulsar los programas de } \\
\text { titulación colectiva que se } \\
\text { adelanten en favor de estas } \\
\text { comunidades. }\end{array}$ & $\begin{array}{l}\text { Contribuir a la solución de los } \\
\text { problemas de tierras que afectan } \\
\text { a las comunidades que represen- } \\
\text { tan (sic) de todo el país e impulsar } \\
\text { los programas de titulación colec- } \\
\text { tiva que se adelanten en favor de } \\
\text { estas comunidades. }\end{array}$ & No \\
\hline $\begin{array}{l}\text { 5. Establecer mecanismos } \\
\text { de coordinación con las } \\
\text { autoridades y entidades } \\
\text { nacionales y territoriales para } \\
\text { hacer efectivo el cumplimiento } \\
\text { de los derechos sociales, } \\
\text { económicos, políticos, } \\
\text { culturales y territoriales de las } \\
\text { Comunidades Negras; }\end{array}$ & & $\begin{array}{l}\text { Establecer mecanismos de co- } \\
\text { ordinación con las autoridades } \\
\text { y entidades nacionales y ter- } \\
\text { ritoriales para hacer efectivo el } \\
\text { cumplimiento de los derechos } \\
\text { sociales, económicos, políticos, } \\
\text { culturales y territoriales de las co- } \\
\text { munidades que representan (sic). }\end{array}$ & No \\
\hline
\end{tabular}


Cuadro 1. Modificación de las funciones otorgadas a la Comisión Consultiva de Alto Nivel a través de sus decretos reglamentarios

\begin{tabular}{|c|c|c|c|}
\hline Decreto 1371 de 1994 & Decreto 2248 de 1995 & Decreto 3770 de 2008 & $\begin{array}{l}\text { Surtió la con- } \\
\text { sulta previa }\end{array}$ \\
\hline $\begin{array}{l}\text { 6. Buscar consensos y acuerdos } \\
\text { entre las comunidades negras y } \\
\text { el Estado, dentro del marco y sin } \\
\text { detrimento de la autonomía de } \\
\text { la administración pública y de la } \\
\text { utilización de los mecanismos } \\
\text { de participación ciudadana; }\end{array}$ & & $\begin{array}{l}\text { Buscar consensos y acuerdos en- } \\
\text { tre las comunidades que repre- } \\
\text { sentan (sic) y el Estado, dentro } \\
\text { del marco de la democracia par- } \\
\text { ticipativa y de la utilización de } \\
\text { los mecanismos de participación } \\
\text { ciudadana y comunitaria, sin det- } \\
\text { rimento de la autonomía de la ad- } \\
\text { ministración pública. }\end{array}$ & No \\
\hline $\begin{array}{l}\text { 7. En materia de reglamentación } \\
\text { de la Ley } 70 \text { de 1993, } \\
\text { constituirse en el espacio para } \\
\text { que las Comunidades Negras } \\
\text { presenten y debatan con los } \\
\text { representantes del Gobierno } \\
\text { Nacional las recomendaciones } \\
\text { pertinentes, antes de que los } \\
\text { proyectos respectivos sean } \\
\text { expedidos por el Presidente } \\
\text { de la República. Dentro de } \\
\text { estos parámetros, la Comisión } \\
\text { Consultiva de Alto Nivel } \\
\text { deberá promover la difusión, } \\
\text { consulta y participación de } \\
\text { las Comunidades Negras } \\
\text { y sus organizaciones en la } \\
\text { reglamentación de la Ley } 70 \\
\text { de } 1993 \text {. Así mismo realizará el } \\
\text { seguimiento y evaluación del } \\
\text { desarrollo de la Ley. }\end{array}$ & $\begin{array}{l}\text { 7. Servir de espacio para el } \\
\text { debate de los proyectos de } \\
\text { decretos reglamentarios de la } \\
\text { Ley } 70 \text { de } 1993 \text {, antes de que } \\
\text { los mismos sean sometidos a } \\
\text { la consideración del Gobierno } \\
\text { Nacional. A ese efecto la Co- } \\
\text { misión deberá promover la di- } \\
\text { fusión y consulta de tales pro- } \\
\text { yectos con las organizaciones } \\
\text { de base de las comunidades }\end{array}$ & $\begin{array}{l}\text { Servir de instancia de consulta } \\
\text { previa de medidas legislativas o } \\
\text { administrativas, del ámbito De- } \\
\text { partamental o Distrital, según } \\
\text { proceda, susceptibles de afec- } \\
\text { tar directamente a las Comuni- } \\
\text { dades Negras, Afrocolombianas, } \\
\text { Raizales o Palenqueras, de con- } \\
\text { formidad con la Ley } 21 \text { de } 1991, \\
\text { aprobatoria del Convenio } 169 \text { de } \\
\text { la OlT, sobre pueblos indígenas y } \\
\text { tribales en países independientes. }\end{array}$ & \\
\hline
\end{tabular}

Como se observa en el cuadro, fue en el año 2008, durante el gobierno del presidente Álvaro Uribe Vélez, cuando se presentó la mayor modificación de las funciones de la Comisión Consultiva de Alto Nivel, al identificarla como instancia de consulta previa de medidas legislativas (Decreto 3770 de 2008). Este cambio puede ser entendido como respuesta del Gobierno a la sentencia C-030 del 23 de enero de 2008, que declaró inexequible la Ley Forestal, y la senten- cia C-461 del catorce de mayo de dos mil ocho que declaró exequible el Plan Nacional de Desarrollo 2006-2010 (Ley 1151 de 2007) siempre que suspendiera "la ejecución de cada uno de los proyectos, programas o presupuestos plurianuales incluidos en la misma que tengan la potencialidad de incidir directa y específicamente sobre pueblos indígenas o comunidades étnicas Afrodescendientes, hasta tanto se realice en forma integral y completa la consulta 
previa específica exigida por el bloque de constitucionalidad". Estas y otras sentencias provocaron duros golpes a las políticas trazadas por el presidente Uribe Vélez y una manera rápida de evitar nuevas demandas fue consolidar la Comisión Consultiva de Alto Nivel como instancia de consulta previa de medidas legislativas, con lo cual lo único que se logró fue agravar los problemas de representación y participación de los afrocolombianos, ya que las comunidades de base han tenido que iniciar todo tipo de acciones legales y políticas para demostrar que esta fue creada sin consultarlas, que tampoco fue facultada para suplantarlos en los procesos de consulta previa y que, además, su carácter va en contravía de la forma tradicional de liderazgo de sus comunidades ${ }^{1}$ al constituirla en órgano representativo a la manera de una democracia electoral, con el agravante que se omite lo estipulado en la costumbre y la ley de comunidades negras, donde la elección de interlocutores y beneficiarios se realiza por consenso (Ley 70 de 1993).

Pero esta definición de la Comisión Consultiva de Alto Nivel como espacio de consulta previa va también en contravía de los estándares nacionales e internacionales que estipulan: "se debe consultar a los pueblos interesados, mediante procedimientos apropiados y en particular a través de sus instituciones representativas" (Convenio 169 de la oit, artículo 6).

1 En las comunidades negras, afrocolombianas, palenqueras y raizales no se habla de un líder que sea un representante, es decir, no puede decidir en nombre de la colectividad; se habla de unos emisarios que ejercen un liderazgo correspondiendo este a un mecanismo de interlocución, pero no a una cesión de la representación.
La legitimidad y la representatividad de una autoridad le corresponden al pueblo o a la comunidad beneficiaria, y no puede ni debe el Estado colombiano asumir o definir por sí mismo a quien reconocerá como autoridad legítima. La expedición inconsulta de este Decreto evidencia la poca claridad que existe frente a quién puede ser el representante legítimo de los afrocolombianos. Así lo definió el Consejo de Estado al considerar el estatus de la Comisión Consultiva, mediante sentencia con radicación núm. 110010324000 20070003900 de 5 de agosto de 2010, Sala de Io Contencioso Administrativo, Sección Primera, con Ponencia del magistrado Rafael E. Ostau de Lafont Pianeta. Alli el Consejo de Estado declaró inexequibles los apartes y disposiciones donde se integre la palabra organizaciones de base en la convocatoria a la conformación de la Comisión Consultiva de Alto Nivel. A partir de esta sentencia era necesario reiniciar el proceso de identificación y consolidación del órgano que ejercería la representación de los afrocolombianos en reemplazo de la Comisión Consultiva vigente en ese momento; no obstante, el Ministerio del Interior hizo su propia interpretación y señaló que esta estaría vigente hasta terminar su periodo, esto es, hasta octubre de 2011.

En los diferentes procesos de consulta previa con población negra, Afrocolombiana, palenquera y raizal se evidenciaron inconformidades de Ios Consejos Comunitarios y organizaciones tradicionales e incluso de los organismos de control, quienes cuestionaron no solo la legalidad de la Comisión Consultiva elegida en el 2008 sino también el pretender considerarla como la única instancia de consulta previa, usurpando 
el lugar de la población afrocolombiana de base en la toma de decisiones sobre asuntos que por su naturaleza debían ser objeto de consulta con las comunidades. Tal es el caso de la Ley de Víctimas y el Decreto con fuerza de ley para la Atención, Reparación y Restitución de los derechos de las víctimas negras, afrocolombianas, palenqueras y raizales.

\section{EL CASO DE LA CONSULTA DEL DECRETO-LEY}

Uno de los estandartes de la campaña del presidente Juan Manuel Santos fueron la Ley de Víctimas y el proceso de reconciliación. Era tal su compromiso con esta ley que cuando como jefe de Estado radicó el proyecto señaló que "si lograba aprobar esa normativa habría valido la pena haber sido presidente" (Semana, 10 de junio de 2011). En la prisa por iniciar el proceso para su aprobación se pasó por alto realizar la consulta previa con los pueblos indígenas, con el pueblo Rom y con la población afrocolombiana, requisito que debía surtirse antes de radicar el proyecto de ley.

Para salvar el problema el Gobierno planteó diversas alternativas, una de ellas fue excluir de la Ley de Víctimas a los pueblos étnicos y expedir una ley exclusiva para ellos, propuesta que resultaba improcedente ya que implicaba retrasar la atención y reparación de las víctimas étnicas. Se sugirió entonces una alternativa distinta pero igualmente riesgosa: proponer a los pueblos indígenas que se solicitaría al Congreso de la República otorgar facultades extraordinarias al Presidente de la República, para "expedir por medio de decretos con fuerza de ley la regulación de los derechos y garantías de las víctimas pertenecientes a los pueblos y comunidades indígenas...". La respuesta de los indígenas: "No queremos que un proyecto como este, que es para la reparación integral de todas las víctimas, se caiga por la falta de la consulta" (Semana, 22 de noviembre de 2010).

La propuesta quedó reflejada en la inclusión del artículo 205 de la Ley 1448 de 2011 que, como señalamos anteriormente pretendió salvar el problema de la falta de consulta de la Ley de Víctimas, en un momento en el que, primero, era evidente que había que consultar por el impacto del conflicto en la población afrocolombiana, pueblos indígenas y pueblo Rom; y, segundo, existía un alto riesgo de que la Corte Constitucional la declarara inconstitucional por falta de consulta previa.

Al interior del movimiento afrocolombiano y en buena parte de la sociedad colombiana aun existen cuestionamientos por las dificultades e incluso por la imposibilidad que tuvo esta población para desarrollar un adecuado proceso de consulta de este decreto reglamentario (Decreto 4635 de 2011); en cambio, para los indígenas y los Rom este fue menos traumático y mucho más participativo. En efecto, mientras que los afrocolombianos han estado inmersos en un gran debate interno que busca solucionar los problemas de legitimidad de la Comisión Consultiva de Alto Nivel, los indígenas han estado representados sin mayores sobresaltos por la Mesa Permanente de Concertación. 
Una de las principales razones del éxito de los pueblos indígenas es que estos cuentan con la Mesa Permanente de Concertación, instancia que fue creada mediante el Decreto 1396 de 1997. Estos dieciséis años de experiencia y desarrollo de diversos procesos de consulta previa y concertaciones de distinta índole con el Gobierno Nacional les han servido para fortalecer este escenario como órgano de representación que, además, les permite contar con el acompañamiento permanente de expertos en diversas áreas que facilitan el análisis de los temas de consulta. De otra parte, es probable que esta forma de representación de los pueblos indígenas, a pesar de sus enormes diferencias, sea más cercana al sistema occidental, cuestión que seguramente se debe, por lo menos en parte, a la larga historia de interlocución de cabildos y gobernadores indígenas con los gobiernos colonial y republicano. Esto se refleja, por ejemplo, en el funcionamiento del actual movimiento indígena, liderado por autoridades tradicionales y por organizaciones que, como la onIc, además del estatus interno de autoridades gozan del correspondiente poder de representación.

Es decir, en el caso de los afrocolombianos uno de los principales obstáculos para el proceso de consulta previa del Decreto Ley de Víctimas (Decreto 4635 de 2011) fue la decisión del Gobierno de reconocer exclusivamente la Comisión Consultiva de Alto Nivel como instancia de interlocución y representación. Esta, a pesar de haber sido muy debatida, aprobó en nombre de la población afrocolombiana la inclusión del artículo 205 de la Ley 1448 de 2011 sin realizar ningún tipo de consulta con las comunidades de base.
Una vez expedida la Ley 1448 de 2011, el Gobierno Nacional a través de la Dirección de Comunidades Negras del Ministerio del Interior convocó a la Comisión Consultiva de Alto Nivel de Comunidades Negras a una sesión donde presentó la propuesta de adelantar la formulación de un decreto con fuerza de ley para la atención, reparación y restitución de los derechos de las víctimas pertenecientes a comunidades negras, afrocolombianas, raizales y palenqueras. En esta reunión la plenaria de la Comisión Consultiva de Alto Nivel delegó a la Subcomisión Jurídica y de Derechos Humanos para que adelantara el trabajo técnico de formulación del decreto con las entidades del Gobierno y definiera la ruta de consulta en los niveles regionales y locales (PCN, 2011). Esta adelantó el trabajo encomendado pero olvidó contar con la participación de las comunidades de base.

Ante esta situación las organizaciones de orden nacional defensoras de derechos humanos de las comunidades negras, afrocolombianas, raizales y palenqueras -Conferencia Nacional de Organizaciones Afrocolombianas (CNOA), Movimiento Nacional Cimarrón, Proceso de Comunidades Negras y Asociación de Afrodescendientes Desplazados (AFRODES) - en diferentes escenarios plantearon sus objeciones al Gobierno Nacional por haber adelantado el proceso de consulta previa del decreto únicamente con la Comisión Consultiva Nacional de Alto Nivel y enviaron comunicados a diferentes instancias nacionales e internacionales donde denunciaban no solo las dificultades y la demora en iniciar el proceso conjunto de elaboración del decreto sino la exclusión de las comunidades de base 
del proceso de consulta previa (PCN, 2011). Además, como integrantes de la Mesa Nacional de Organizaciones Afrocolombianas (la Mesa) realizaron una consulta paralela con el apoyo de algunas agencias de cooperación internacional: en el 2011 y 2012 adelantaron un proceso regional y local con diferentes Consejos Comunitarios y organizaciones afrocolombianas de base de Quibdó, Cali, Cartagena, Bogotá y Tumaco cuyo resultado fue una "Propuesta de Decreto Ley para las víctimas afrocolombianas, negras, palenqueras y raizales..." presentada en un evento nacional realizado el 12 de octubre de 2012, en el que participaron la Oficina Delegada para Asuntos Étnicos de la Defensoría del Pueblo, la Procuraduría General de la Nación y la organización internacional wola (Washington Office on Latin America).

La consulta paralela arrancó el 2 de julio de 2011 no sin complicaciones. El 8 de julio de 2011 se dio inicio en Quibdó, Cali, Cartagena, Bogotá y Tumaco a los talleres en los que se esperaba recoger información para la elaboración de una propuesta de decreto por parte de la Mesa. El grupo tuvo dificultades importantes para armonizar las metodologías de taller utilizadas en el pasado para diagnosticar la situación con las de los talleres actuales que apuntaban a una propuesta de reparación. Aún así se recogieron ideas que se sistematizaron en sendas relatorías.

A partir de las relatorías los asesores debían construir un proyecto de decreto que sería validado en una reunión general en Bogotá, a la que concurrirían los delegados de cada región participante. Este proceso resultó más complejo de lo planteado inicialmente por lo que se acudió al apoyo de personas externas al movimiento, expertas en el tema y solidarias con el pueblo afrocolombiano. El 12 de octubre de 2011 la Mesa presentó públicamente su propuesta de decreto y solicitó al Gobierno Nacional utilizarla como insumo para el proceso de consulta previa del decreto reglamentario de la Ley de Víctimas,

Por solicitud expresa de la Mesa, la Defensoría Delegada para Asuntos Étnicos promovió un acercamiento entre los representantes de las organizaciones antes mencionadas con un integrante de la Subcomisión Jurídica y de Derechos Humanos, con el fin de explorar la posibilidad de generar un espacio ampliado en donde participaran la Comisión Consultiva de Alto Nivel y la Mesa, para formular de manera conjunta el texto del decreto ley y definir una ruta concertada para adelantar el proceso de consulta previa en lo regional y local, con la participación de los Consejos Comunitarios de Comunidades $\mathrm{Ne}$ gras, afrocolombianas, palenqueras y raizales y sus organizaciones de base. ${ }^{2}$ A pesar de haberse realizado este acercamiento no fue posible llegar a acuerdos que permitieran avanzar en un proceso unificado.

2 Comunicación oficial enviada el 27 de octubre de 2011 por el Dr. Horacio Guerrero García, defensor delegado para Indígenas y Minorías Étnicas, al Dr. Danilo Valbuena, coordinador delegado para Asuntos Étnicos de la Procuraduría General de la Nación; comunicación de la Procuraduría General de la Nación dirigida al Dr. Juan Fernando Londoño Osorio, viceministro para la Participación e Igualdad de Derechos Proceso de Comunidades Negras (08 de diciembre de 2011). Obtenida de denuncia publica por violación al derecho de la Consulta Previa de los pueblos afros. Recuperada de http://dl.dropbox.com/u/31557764/ PCN\%20Petici\%C3\%B3n\%20a\%20la\%20Procuraduria\%20sobre\%20 Consulta\%20Previa\%202011.pdf 
Mientras tanto, el proceso de revisión y ajustes del proyecto de decreto ley elaborado por la Comisión Consultiva de Alto Nivel y el Gobierno avanzó al interior de la Subcomisión Jurídica sin la participación de la Mesa, y durante el mes de octubre el Gobierno Nacional coordinó la realización de diferentes reuniones con las comisiones consultivas departamentales para su socialización y la recolección de los aportes por parte de las organizaciones de comunidades negras, afrocolombianas, raizales y palenqueras.

La Defensoría, la Procuraduría y diversos medios de comunicación recibieron comunicaciones enviadas por representantes de Consejos Comunitarios y organizaciones de base en las que manifestaban su desacuerdo con el proceso que se venía adelantando por parte del Gobierno Nacional; incluso se conoció un escrito de los Consejos Comunitarios del departamento de Nariño en el cual manifestaban que no participarían en la reunión de la Comisión Consultiva Departamental ya que se estaba aprovechando estos espacios no solo para consultar la propuesta de Decreto Ley de Víctimas afrocolombianas sino otros proyectos de ley de gran trascendencia e impacto al interior de estas comunidades.

Entre los cuestionamientos mencionados resaltamos la comunicación oficial enviada el 27 de octubre de 2011 por el Dr. Horacio Guerrero García, defensor delegado para Indígenas y Minorías Étnicas, al Dr. Danilo Valbuena, coordinador delegado para Asuntos Étnicos de la Procuraduría General de la Nación. En esta carta el defensor menciona algunas de las situaciones que deslegitiman el proceso de consulta pre- via de este decreto y el incumplimiento de los acuerdos verbales alcanzados el 26 de octubre de 2011 entre el viceministro de la Participación, el director de Asuntos para Comunidades Negras, Dr. Boris Zapata, y los representantes de la Mesa; recalca también que la finalidad de estos acuerdos era dar viabilidad a un proceso tan importante para las comunidades negras, afrocolombianas, palenqueras y raizales. Estos eventos y acuerdos mencionados por el Dr. Horacio Guerrero García en su comunicación fueron desconocidos por el Dr. Boris Zapata, tanto así, que el día 31 de octubre de 2011 (7 días después de la reunión mencionada) se protocolizó con la Comisión Consultiva de Alto Nivel el proceso de consulta del proyecto de decreto con fuerza de ley para la atención, reparación y restitución de los derechos de las víctimas negras, afrocolombianas, palenqueras y raizales sin atender las solicitudes presentadas por las organizaciones que conforman la Mesa de organizaciones afrocolombianas, desconociéndose de esa manera su derecho a la participación y el acuerdo celebrado el día 26 de octubre de 2011.

Teniendo en cuenta los hechos señalados, la Procuraduría General de la Nación envió comunicación al doctor Juan Fernando Londoño Osorio, viceministro para la Participación e lgualdad de Derechos, solicitándole que se surtiera adecuadamente el proceso de consulta previa con todos los sectores interesados. ${ }^{3}$ Hasta la fecha

3 Esta solicitud fue formulada en ejercicio de las funciones que en el ámbito del control preventivo le fueron otorgadas mediante el Decreto Ley 262 de 2000, en concordancia con lo dispuesto en la Resolución No. 017 expedida por el señor Procurador General de la Nación el 4 de marzo del mismo año. 
no se conocen los resultados de estas investigaciones, pero existe un decreto reglamentario que no surtió un proceso adecuado de consulta previa y que dejó enseñanzas conjuntas al Gobierno Nacional y al movimiento afrocolombiano respecto de los pasos que se deben cumplir. A continuación se presentan los cuatro pasos que facilitarían los procesos de consulta previa de normas de carácter nacional y que buscan incorporar las lecciones aprendidas durante "la consulta" del decreto ley de víctimas afrocolombianas, palenqueras y raizales.

\section{III. ¿CÓMO HACER LA CONSULTA CON EL SUJETO COLECTIVO AFROCOLOM- BIANO? CONSIDERACIONES PARA UNA PROPUESTA DE REGLAMENTACIÓN}

La materialización de la consulta previa a la población afrocolombiana desarrolla el derecho que esta tiene de conservar y reforzar sus instituciones propias y de participar plenamente en las decisiones que atañen a su vida política, económica y cultural. Para hacer efectivo este derecho es necesario: primero, identificar las comunidades donde se realizará la consulta; segundo, identificar los actores representativos en cada comunidad; tercero, garantizar el suficiente tiempo para cada proceso de consulta; y cuarto, garantizar una adecuada respuesta del Gobierno a las decisiones de la población afrocolombiana. Estas consideraciones deben estar reflejadas en una ruta de consulta de normas de nivel nacional que evite las dificultades de la consulta del Decreto 4635 de 2011, ruta que se sugiere en esta sección.

\section{A. Primer paso: identificar las comuni- dades donde se realizará la consulta}

Cuando la consulta previa corresponda a acciones o afectaciones puntuales focalizadas en comunidades específicas se debe realizar con esas comunidades, atendiendo a sus formas propias de gobierno y a los mecanismos de participación por ellas establecidas.

Para el caso de los proyectos de ley o decisiones que correspondan al orden nacional, como los planes de desarrollo, el proceso de consulta se debe dividir de manera territorial incluyendo urbes, zonas rurales e islas de manera que los sitios de encuentro faciliten la participación tanto de comunidades rurales como de colectivos urbanos.

\section{B. Segundo paso: identificación de los actores en cada comunidad}

La identificación de las autoridades representativas en cada comunidad es uno de los mayores retos a la hora de garantizar el derecho a la consulta previa y el consentimiento previo libre e informado. En el caso de los afrocolombianos es importante tener en cuenta que ellos no funcionan con una estructura jerárquica en que los líderes son, además, representantes; por lo tanto, se debe recurrir directamente a las comunidades, como lo dice la Ley 70 de 1993: “La participación de las comunidades negras y sus organizaciones...". Allí se habla de la participación de las comunidades sin limitarlas, y hace referencia a los Consejos Comunitarios por ser en su momento quienes representaban a la po- 
blación afrocolombiana de las zonas rurales y ribereñas, mientras las organizaciones (sin definirlas de manera explícita) serían aquellas que facilitan la interlocución de las comunidades con las autoridades locales y nacionales.

¿Quiénes son los miembros de la comunidad? Las comunidades negras y los ascendientes afrocolombianos, tal como lo establece la Ley 70 de 1993, corresponden al "conjunto de familias de ascendencia Afrocolombiana que poseen una cultura propia, comparten una historia y tienen sus propias tradiciones y costumbres dentro de la relación campo-poblado, que revelan y conservan conciencia de identidad que las distinguen de otros grupos étnicos." Es decir, todas aquellas personas que se autoidentifiquen como miembros de la comunidad negra y que mantengan las prácticas sociales y culturales tradicionales son susceptibles de participar en un proceso de consulta, ¿pero, quiénes son estas personas?

Un primer paso para identificarlas implica una reflexión interna de la población afrocolombiana, de tal manera que se alcance un consenso que permita determinar si se está hablando del 10.4 $\%{ }^{4}$ de la población que se reconoce como negra, afrocolombiana, palenquera y raizal (DANE, CIDSE, 2005) o es necesario el ejercicio de la identidad étnica y racial. La pregunta de fondo es: ¿todos caben o deberían caber dentro del sujeto colectivo afrocolombiano a ser consultado, toda vez que existen personas que fenotípica y racialmen-

4 Dato que incluye afrocolombianos ubicados en zonas rurales, urbanas $\mathrm{e}$ islas. te pueden ser encasilladas como afrocolombianas sin que hayan desarrollado ningún tipo de identidad individual o colectiva con este grupo? Atendiendo a lo establecido en la sentencia C-169 de 2001, si siempre se han identificado como mestizos no deberían ser considerados dentro del proceso de consulta previa.

La justificación de la consulta del sujeto colectivo afro no es estrictamente racial; por la forma en que se ha construido la identidad negra en Colombia tiene un componente de identidad cultural que no necesariamente es compartido por todas las personas que tienen ascendencia, y se reconocen, como afrocolombianos (sentencia C-169 de 2001). Este componente étnico se funda en unos vínculos históricos con un territorio; unos modos específicos de apropiarse, de convivir y aprovechar el territorio; una historia colectiva en ese lugar con tradiciones y valores que distinguen a estas comunidades del resto de la sociedad (от, 2009), definición que no incluye a otros afrocolombianos que no tienen este tipo de identidad ni pertenencia comunitaria. Sin embargo, esto no quiere decir que en aplicación de la sentencia del Consejo de Estado el Gobierno Nacional deba limitar la representación de las comunidades negras a aquellas que están constituidas en Consejos Comunitarios y tienen un título colectivo reconocido, ya que esto pondría en grave riesgo su supervivencia física y cultural.

Existe un antecedente exitoso que fue el proceso de formulación del articulado que se convertiría en la Ley 70 de 1993. En esa oportunidad se acudió a los líderes veredales, juntas de acción 
comunal y otros líderes de los ríos del Pacífico biogeográfico y con ellos se coordinó el desarrollo de una serie de conversatorios locales que convocaron una gran cantidad de población, entre la que se socializaron los logros alcanzados en la Constitución de 1991 y conjuntamente se elaboró el texto de la ley que visibilizaría y garantizaría derechos de las comunidades negras: la Ley 70 de 1993.

Como ya se mencionó, las convocatorias de estos conversatorios combinaron estrategias lúdicas (grupos de danza, obras de teatro) y medios tradicionales de comunicación como telegramas y encomiendas con personas relevantes de la comunidad, con el propósito de garantizar la mayor participación local. Allí se designaron unos representantes que participaron en las reuniones regionales y estaban obligados a no tomar decisiones autónomas sino a trasmitir toda la información posible a los espacios locales donde las comunidades, en pleno, tomaban decisiones escuchando los consejos de los mayores y las ideas de los jóvenes (Grueso, 2000).

Estas reuniones locales se desarrollaron en grupos de trabajo que discutían cada tema a incluir en la ley. Los grupos de trabajo estaban conformados por voceros designados por las diferentes regiones, que luego de las discusiones locales se trasladaban con los insumos regionales a Bogotá para discutir la reglamentación. En estos grupos se encontraban miembros de la comunidad sin formación académica pero con un amplio conocimiento ancestral y tradicional, académicos afrocolombianos y mestizos que sintetizaban y apoyaban el proceso de redacción del articulado teniendo como objetivo central plasmar las necesidades y propuestas que surgían, desde el elemento ancestral y cultural hasta el elemento político. Si bien la Ley 70 de 1993 no quedó exactamente como deseaban las comunidades, por lo menos una buena parte de las discusiones y aportes comunitarios sí quedaron plasmados en ella.

Garantizar una participación real de los afrocolombianos es una tarea ardua pero posible, que implica mirar atrás y evaluar las metodologías creadas e implementadas por ellos para comunicarse y para construir sus estrategias de resistencia y de desarrollo, como sucedió con la Ley 70 de 1993. La forma de identificar el sujeto de la consulta será acorde con las tradiciones afrocolombianas, siguiendo además la línea de lo ordenado por la Corte Interamericana de Derechos Humanos (CIDH), que en la sentencia Caso del pueblo Saramaka vs. Surinam (2007) estableció: "El Estado tiene el deber de consultar, activamente, con dicha comunidad, según sus costumbres y tradiciones".

\section{Tercer paso: garantizar el suficiente tiempo en cada proceso de consulta}

La consulta previa de un proyecto de ley que impactará la población afrocolombiana de todo el país requiere un marco de tiempo amplio para el desarrollo de todas las fases del proceso de consulta. En primer lugar, como no existe una metodología definida con la comunidad, se debe iniciar un proceso de preconsulta para determinar la metodología y poder desarrollar la 
consulta con todas las garantías legales y constitucionales. Este paso se puede obviar siempre que exista una ruta predeterminada para la consulta de normas de nivel nacional, debidamente acordada.

Pero aun existiendo una ruta predeterminada hay que disponer de suficiente tiempo para todas las etapas. Primero, se debe garantizar que la población afrocolombiana conozca con suficiente antelación el articulado del proyecto y aquellos elementos que incidirán en los aspectos sociales, políticos, culturales y económicos de las comunidades. Como muchas leyes incluyen aspectos técnicos complejos, incluso para los abogados, es necesario contar con el apoyo de uno o varios equipos independientes que puedan hacer comprensible el proyecto o propuesta objeto de la consulta. Las universidades y los organismos internacionales especializados han demostrado experiencia, independencia, fiabilidad y capacidad para desarrollar estrategias pedagógicas acordes con las características y necesidades propias de estas comunidades, y se puede contar con ellos de forma más o menos permanente.

De igual manera, es necesaria una trasmisión de toda la información relevante. El Gobierno Nacional a través del grupo de consulta del Ministerio del Interior debe "suministrarle a las personas oportunamente toda la información que no goce de reserva constitucional o legal; advirtiendo sí, que esta información oficial debe ser completa, consistente, coherente, verificable, comparable, contextualizada, diáfana y siempre oportuna" (sentencia C-891 de 2002). Es decir que, atendiendo a lo definido por el principio de oportunidad y el derecho a la información, las comunidades deben ser informadas de la necesidad o intención de desarrollar un proyecto de ley o actividad en sus territorios o que implique la afectación a los derechos étnicos diferenciales. Esta información debe enviarse en el momento mismo en que se inicie la elaboración de la propuesta y no después de radicada.

Los tiempos deben ser suficientes para garantizar un espacio colectivo para: (I) la presentación de la propuesta por parte del Gobierno Nacional, de los conceptos de los organismos independientes y el análisis integral por los miembros de las comunidades; (II) la discusión y análisis respecto de la procedencia o no de la propuesta y las posibles alternativas o modificaciones, lo cual implica la posibilidad de varias reuniones con comunidades de todo el orden nacional para conocer sus percepciones y definir si desean emitir propuestas y conceptos conjuntos o si cada comunidad realizará sus intervenciones de manera independiente.

El Gobierno Nacional debe recibir propuestas de la población afrocolombiana, analizar su alcance y viabilidad e integrarlas de manera conjunta con los representantes delegados por cada comunidad y los veedores independientes al proyecto o acto inicial. Una vez integradas las propuestas el nuevo texto debe ser presentado a las comunidades para su aprobación o negación; esta etapa puede requerir dos o más reuniones. Los puntos de disenso que se identifiquen en las diferentes propuestas deberán ser integrados al proyecto, tratando de garantizar, en la medida de lo po- 
sible, la protección, respuesta y aclaración que estos requieran (Rodríguez, 2009).

Por lo tanto, el tiempo de consulta es necesariamente de varios meses. En términos generales se está hablando de tres o cuatro meses, por lo menos, a partir del momento en que el Gobierno Nacional y los veedores independientes presentan la propuesta inicial de forma simultánea en todas las comunidades. Esto no incluye el tiempo que toma armar la explicación de la norma con toda su complejidad ni radicar, sistematizar y responder los comentarios recibidos, que podría ser, mínimo, otros tres meses. Tampoco está contemplada en estos tiempos la posibilidad de consultar varias normas complejas a la vez, hecho que agotaría la posibilidad de respuesta de las comunidades.

En los primeros tres meses está incluida la preidentificación de los medios adecuados de comunicación. Si bien el internet es de acceso fácil y rápido, se debe tener en cuenta las comunidades que se encuentran ubicadas en zonas rurales o ribereñas donde no se dispone de energía permanente y el uso de medios electrónicos es limitado, para hacerles llegar las convocatorias, documentos, propuestas y proyectos en físico y en un número de copias suficiente para los diferentes procesos organizativos.

Por otro lado, las entidades locales y el Ministerio del Interior deben encargarse de realizar convocatorias claras, indicando la fecha, el lugar, los temas a tratar y los responsables de su presentación y debate; además, deben garantizar la entrega inmediata de la relatoría de las reuniones para que esta sea aprobada por los participantes.

Como se ve, difícilmente se puede establecer el tiempo promedio que requiere un proceso de consulta. Para las comunidades lo importante no es el tiempo sino la calidad de las acciones, la intención de los participantes y la calidad de la comunicación, toda vez que lo que se pretende es que haya un diálogo entre iguales donde se busca la salida menos nociva, no se trata de una carrera.

\section{Cuarto paso: garantizar una adecua- da respuesta del Gobierno a las decisio- nes de la población afrocolombiana}

El objetivo principal de un proceso de consulta es llegar a un punto de equilibrio donde se logre construir la alternativa menos nociva para las comunidades. Por eso es tan importante la participación de estas en la fase de proyección, implementación y desarrollo de estrategias de mitigación de los impactos identificados.

En esta fase encontramos dos escenarios. El primero es aquel en que muchas o todas las comunidades consultadas rechazan la norma o apartes de esta porque consideran que afecta de manera grave sus relaciones sociales y culturales poniendo en riesgo su supervivencia como grupo étnico diferencial. En este caso el Gobierno debe considerar reformular el proyecto para subsanar aquellos elementos que lo hacen poco viable a los ojos de la comunidad negra, y hacerlo de buena fe dándole una debida consideración a la voluntad de las comunidades. De no 
hacerlo, debe probar por qué considera lo contrario, ya que la Corte Constitucional ha sostenido que el consentimiento es obligatorio en los casos en los que se ponga en peligro la supervivencia del grupo (sentencia T-129 de 2011). En el segundo escenario todas o la mayoría de las comunidades consultadas definen que pese a la existencia de unos impactos sociales, culturales o ambientales el proyecto es viable y debe implementarse mediante la adopción de ciertas recomendaciones. En este caso es necesario el establecimiento de acuerdos y compromisos que permitan salvaguardar los derechos de la población afrocolombiana, y son los veedores internacionales y el Ministerio Público quienes deben garantizar no solo el cumplimiento de tales acuerdos, sino que estos tengan un carácter vinculante para los participantes y se reflejen en la normatividad adoptada. Los veedores deben presentar una propuesta de ruta de seguimiento para controlar que dichos acuerdos y compromisos se están cumpliendo y comprometerse a desarrollar las acciones legales correspondientes cuando estos sean vulnerados por los participantes en el proceso de consulta.

\section{e) Precondición: garantizar la adecuada financiación de la consulta}

Mucho se ha hablado de lo costoso que resulta para el Estado colombiano el desarrollo de los procesos de consulta. Una alternativa sería diseñar una ruta de consulta nacional para definir la metodología a seguir en la consulta de proyectos de ley y proyectos de desarrollo; para esto, los miembros del Gobierno y el equipo independiente mencionado deben hacer un reco- rrido por cada zona donde según los datos censales se encuentre la población afrocolombiana y definir con estas comunidades, de forma previa, las dos metodologías de consulta (de proyectos de ley y de proyectos de desarrollo). Esto permitiría tener un estimado de los costos que deberán destinarse en adelante para el equipo de expertos que diseñe la estrategia de comunicación de la norma en consulta, para los viajes y reuniones, cuyo costo puede ser previsto y racionalizado una vez se cuente con la ruta del caso.

Un nuevo mecanismo transitorio en materia de representación e interlocución de la población afrocolombiana surgió en agosto de 2013, en el marco del Primer Congreso Nacional AfrocoIombiano, evento que reunió cerca de 1.050 líderes y lideresas afrocolombianas de todo el territorio nacional. Allí se eligió la Autoridad Nacional Afrocolombiana (ANA), integrada por 109 líderes cuyos cupos representan a distintos sectores, así: 55 para Consejos Comunitarios, 32 para los departamentos con población afrocolombiana, 2 para líderes juveniles, 2 para representantes de víctimas, 2 para el Palenque de San Basilio, 3 para los raizales, 1 para población en situación de discapacidad, 2 para representantes de los estudiantes, 5 para los distritos especiales, 1 para los mayores, 1 para la capitanía, 2 para las mujeres y por primera vez en la historia se incluyó un cupo para la población LGBTI afrocolombiana.

Este órgano transitorio tendrá una vigencia de seis meses en los cuales debe dar cumplimiento a los mandatos que surgieron del Congreso que 
lo eligió. Entre los retos y lecciones que deberá enfrentar este mecanismo transitorio en materia de consulta previa se resaltan los señalados en el siguiente numeral.

\section{CONCLUSIÓN: LECCIONES APRENDIDAS DENTRO DE LOS PROCESOS DE CONSULTA}

Una de las grandes lecciones corresponde a la validez de la protocolización de una consulta. El Decreto Ley 4635 de 2011 "Por el cual se dictan medidas de asistencia, atención, reparación integral y de restitución de tierras a las víctimas pertenecientes a comunidades negras, afrocolombianas, raizales y palenqueras", si bien fue protocolizado adolece de diversas falencias que hablan de un proceso nulo, pero teniendo en cuenta la trascendencia nacional de la atención y reparación integral hasta este momento no ha sido demandado, es decir, no todo proceso de consulta es válido, no todo proceso de consulta es realizado de manera adecuada, pero aun así, como sucedió en este caso, el Decreto Ley fue protocolizado y corresponde a la población afrocolombiana definir su validez o ineficacia y acudir a las acciones jurídicas y políticas que garanticen el pleno ejercicio de sus derechos.

El afán por identificar y nombrar un interlocutor a dejado amargas experiencias tanto al movimiento afrocolombiano como al Gobierno Nacional, por lo cual es recomendable tomarse el tiempo necesario para garantizar la más amplia y cualificada participación de la población afro- colombiana, que verse obligado a rehacer procesos y leyes.

Los procesos de consulta previa deben compadecerse con los tiempos de consulta y deliberación propios de las comunidades, tiempos que además son los que permiten la consolidación de interlocutores válidos.

Es necesario establecer una ruta de consulta de normas del nivel nacional, que pueda ser utilizada en diversos procesos, en lugar de crearla en cada ocasión. Se debe entender que una buena ruta de consulta para la agenda legislativa requiere tiempo y una elaboración minuciosa que permita no solo integrar a todos los beneficiarios de la consulta sino establecer los mecanismos y los voceros adecuados para estos procesos.

Resguardar la autonomía de los órganos de interlocución garantiza la idoneidad en las decisiones, es decir, la población afrocolombiana y los interlocutores elegidos deben tener la capacidad política de autoconvocarse sin depender de recursos provenientes del Gobierno Nacional, entendiendo que son mecanismos autónomos y no un apéndice de la estructura del Estado; que deben definir claramente sus alcances, el tiempo de funcionamiento, su forma de elección, las formas de seguimiento y control, el sistema de revocatoria del mandato, y especialmente los medios de difusión que le permitan a la población afrocolombiana de todo el territorio nacional no solo conocer los temas discutidos sino establecer su postura frente a ellos. 
Bibliografía

Afrodescendientes. (2013). Memorias Congreso Nacional Afrocolombiano. Recuperado de http://www.afrodescendientes.com/index. php/organizacion-interna/275-congreso-nacional-2013-introduccion

Consejo de Estado, Sala de lo Contencioso Administrativo, Sección Primera. Sentencia de agosto 5 de 2010. C. P.: Rafael E. Ostau de Lafont Pianeta.

Corte Constitucional. Sentencia C-030 de 2008.

M. P.: Rodrigo Escobar Gil.

Corte Constitucional. Sentencia C-1022 de 1999. M. P.: Alejandro Martínez Caballero.

Corte Constitucional. Sentencia C-169 de 2001. M. P.: Carlos Gaviria Díaz.

Corte Constitucional. Sentencia C-169 de 2009. M. P.: Humberto Antonio Sierra Porto.

Corte Constitucional. Sentencia C-461 de 2008. M. P.: Manuel José Cepeda Espinosa.

Corte Constitucional. Sentencia C-530 de 1993. M. P.: Alejandro Martínez Caballero.

Corte Constitucional. Sentencia C-891 de 2002. M. P.: Jaime Araújo Rentería.

Corte Constitucional. Sentencia T-129 de 2011. M. P.: Jorge Iván Palacio.
Corte Constitucional. Sentencia T-174 de 1998.

M. P.: Alejandro Martínez Caballero.

Corte Interamericana de Derechos Humanos. (11 de marzo de 2005). Caso Caesar vs. trinidad y Tobago.

Corte Interamericana de Derechos Humanos. (28 de noviembre de 2007). Caso del Pueblo Saramaka vs. Surinam.

Decreto 1371 de 30 de junio de 1994. "Por el cual se conforma la Comisión Consultiva de Alto Nivel de que trata el artículo 45 de la Ley 70 de 1993".

Decreto 2248 de 22 de diciembre de 1995. "Por el cual se subroga el Decreto 1371 de 1994, se establecen los parámetros para el Registro de Organizaciones de base de las Comunidades Negras y se dictan otras disposiciones".

Decreto 4635 de 9 de diciembre de 2011. “Por el cual se dictan medidas de asistencia, atención, reparación integral y de restitución de tierras a las víctimas pertenecientes a comunidades negras, afrocolombianas, raizales y palenqueras".

Decreto Ley 262 de 22 de febrero de 2000. "Por el cual se modifica la estructura y la organización de la Procuraduría General de la Nación y del Instituto de Estudios del Ministerio Público; el régimen de competencias interno de la Procuraduría General; se dictan normas para su funcionamiento; se modifica el régimen de carrera de la Procuraduría General 
de la Nación, el de inhabilidades e incompatibilidades de sus servidores y se regulan las diversas situaciones administrativas a las que se encuentren sujetos".

Departamento Administrativo Nacional de Estadística y Universidad del Valle. (2005). Análisis regional de los principales indicadores sociodemográficos de la comunidad afrocolombiana e indígena a partir de la información del Censo General 2005. Bogotá: DANE, Univalle-Cidse.

Estupiñan, J. P. (2005). Revista de Información Básica. Recuperado de http://www.dane. gov.co/revista_ib/html_r1/articulo7_r1.htm

Fanon, F. (2009). Piel negra, máscaras blancas. Madrid: Akai.

Grueso, L. R. (2000). El proceso organizativo de comunidades negras en el pacifico sur coIombiano. Cali: Universidad Javeriana.

Ley 1021 de 22 de abril de 2006. Ley Forestal.

Ley 1151 del 24 de julio de 2007. Plan Nacional de Desarrollo 2006 - 2010.

Ley 1382 de 9 de febrero de 2010. Código Minero.

Ley 1448 de 10 de junio de 2011. Ley de Víctimas.

Ley 21 de 1991. (1989). Aprobatoria del Convenio 169 sobre pueblos indígenas y tribales en países independientes, aprobado por la $76^{a}$ reunión de la Conferencia General de la oit. Ginebra: oit.

Ley 70 de 27 de agosto de 1993. "Por la cual se desarrolla el artículo transitorio 55 de la Constitución Política.

Mesa Nacional de Organizaciones Afrocolombianas. (2012). Propuesta de Decreto Ley para las víctimas afrocolombianas, negras, palenqueras y raizales.

Organización Internacional del Trabajo - olt. (Junio 7 de 1989). Convenio 169 sobre pueblos indígenas y tribales en países independientes.

Organización Internacional del Trabajo. (2009). Los derechos de los pueblos indígenas y tribales en la práctica. Una guía sobre el Convenio No. 169 de la ort. Programa para promover el Convenio Núm. 169 de la oIT (PRO 169), Departamento de Normas Internacionales del Trabajo.

Palenque regional El Congal. (2008a). Asamblea Nacional del Proceso de Comunidades Negras.

Proceso de Comunidades Negras - PCN. (08 de diciembre de 2011). Denuncia pública por violación al derecho de la consulta previa de los pueblos afros. Recuperado de http:// dl.dropbox.com/u/31557764/PCN\%20 Petici\%C3\%B3n\%20a\%20la\%20 Procuraduria\%20sobre\%20Consulta\%20Previa\%20 2011.pdf 
Rodríguez, C. y Orduz, N. (2012). Lecciones del proceso de construcción del decreto de reparación y restitución de tierras para pueblos indígenas en Colombia. Bogotá: DeJusticia

Rodríguez, G. A. (Junio, 2009). El papel de la consulta previa en la pervivencia de los pueblos indígenas y demás grupos étnicos de Colombia. El otro derecho, 40, 12.

Rodríguez, G. A. (2010). La consulta previa con pueblos indígenas y comunidades afrodescendientes en Colombia. Bogotá: Universidad del Rosario.

Rodríguez, G. A. (2011). La consulta previa en medidas legislativas.

Semana. (10 de junio de 2011). Presidente Santos sanciona Ley de Víctimas. Recupe- rado de http://www.semana.com/nacion/ articulo/presidente-santos-sanciono-ley-victimas/241121-3

Urrea, F. y Viáfara, C. (16 de febrero de 2012). Estadísticas existentes, territorios colectivos y censo agropecuario 2013. Recuperado de http://es.scribd.com/doc/92385792/ Estadisticas-existentes-territorios-colectivosy-censo-agropecuario-2013

Wabgou, M., Arocha, J., Salgado, A. y Carabalí, J. (2012). Movimiento social afrocolombiano, negro, raizal y palenquero: el largo camino hacia la construcción de espacios comunes y alianzas estratégicas para la incidencia política en Colombia. Bogotá D. C.: Universidad Nacional de Colombia. 